\title{
EFEITOS DE CICLOS DE UMEDECIMENTO E SECAGEM NA REORGANIZAÇÃO DA ESTRUTURA MICROGRANULAR DE LATOSSOLOS ${ }^{(1)}$
}

\author{
J. H. M. VIANA ${ }^{(2)}$, E. I. FERNANDES FILHO ${ }^{(3)}$ \& C. E. G. R. SCHAEFER ${ }^{(3)}$
}

\section{RESUMO}

Um experimento foi realizado em casa de vegetação com o objetivo de examinar as modificaçóes provocadas por ciclos de umedecimento e secagem em amostras de Latossolos com diferentes mineralogias, em agregados integrais ou quando destruídos por moagem. Amostras de terra fina seca ao ar foram passadas em peneira de 1,0 $\mathrm{mm}$ e subdivididas em grupos: solo integral não moído e solo moído em almofariz e passado em peneira de $0,105 \mathrm{~mm}$. O solo moído foi ainda subdividido em solo moído puro ou adicionado de ácido húmico purificado. Os materiais foram montados em cilindro de alumínio e submetidos a dez ciclos sucessivos de umedecimento e secagem, realizados por ascensão capilar, seguidos por secagem ao ar, com intervalo de sete dias entre cada ciclo. Após o término dos ciclos, os solos foram impregnados com resina de poliéster, montando-se seções finas para microscopia, as quais foram levadas para observação em microscópio ótico e fotografadas. As imagens obtidas foram digitalizadas, analisadas e quantificadas por meio do programa QUANTIPORO, desenvolvido no Departamento de Solos/Universidade Federal de Viçosa. Os resultados mostraram completa modificação na forma e no padrão da estrutura após a aplicação dos ciclos nos tratamentos que sofreram destruição de agregados por moagem. Essas mudanças foram atribuídas a uma reacomodação dos agregados fragmentados com a retração do plasma, que se seguiu ao processo de secagem. Todos os materiais estudados mostraram uma estrutura bem diferente da estrutura primária original destes solos. Não se observou qualquer tendência à reversão da estrutura após os dez ciclos, demonstrando que outros fatores, além dos físico-químicos e mineralógicos, devem ser invocados para explicar a gênese de microagregados em Latossolos.

Termos de indexação: agregados, estrutura do solo, microagregado, micromorfologia de solos.

\footnotetext{
(1) Parte da Tese de Mestrado do primeiro autor, apresentada ao Departamento de Solos da Universidade Federal de Viçosa - UFV. Recebido para publicação em março de 2002 e aprovado em novembro de 2003.

(2) Doutorando do Departamento de Solos, Universidade Federal de Viçosa - UFV. CEP 36570-000 Viçosa (MG). E-mail: jherbert@solos.ufv.br

(3) Professor do Departamento de Solos, UFV. E-mails: elp@solos.ufv.br; carlos.schaefer@solos.ufv.br
} 


\title{
SUMMARY: EFFECTS OF WETTING AND DRYING CYCLES ON THE REORGANIZATION OF THE MICROGRANULAR STRUCTURE OF LATOSOLS
}

\begin{abstract}
A greenhouse experiment was conducted to examine the structural modifications engendered by wetting-drying cycles in Latosol samples (Oxisols) with different mineralogical properties submitted to dry grinding, compared with bulk samples. Air-dried soil samples were sieved through a $1.00 \mathrm{~mm}$ sieve and separated in two groups. One was kept as control group and the other ground in a mortar and sieved through a $0.105 \mathrm{~mm}$ sieve. This second was also split in two groups, one of which received particulate humic acid treatment. The materials were placed in aluminum columns, subjected to 10 weekly wetting cycles by capillarity followed by air-drying. At the end of the cycles, the samples were impregnated with polyester resin, cut in blocks and thin-sectioned for microscopy analysis. The sections were scrutinized under optical microscope, photographed, and the images digitalized, analyzed, and quantified with the Software QUANTIPORO. After the wetting and drying cycles, important alterations in both shape and structural pattern were observed in the ground samples. These changes were attributed to a re-organization of soil particles during the plasma shrinkage after the drying process. All materials presented a different structural pattern in relation to the original soil structure. No trend for reversion to the original structure was observed after the cycles. This indicates that other factors besides the physical-chemical and mineralogical should be considered to explain the genesis of Latosol microaggregates.
\end{abstract}

Index terms: aggregation, soil structure, microaggregate, soil micromorphology.

\section{INTRODUÇÃO}

A estrutura e a textura são as propriedades físicas do solo consideradas mais importantes ao crescimento das plantas. A natureza dinâmica da primeira, no entanto, torna o conhecimento dos fatores e mecanismos de sua variação no tempo e no espaço essencial para a modelagem e predição do comportamento do solo em uso.

A formação da estrutura, ou do arranjo espacial das partículas do solo, dá origem aos poros, com importantes conseqüências para o comportamento físico do solo, tais como: a percolação e a difusão de fluidos, a resistência mecânica à ruptura e a penetração de raízes.

O conhecimento desses mecanismos de formação e estabilidade da estrutura ainda é incipiente, principalmente no que se refere a solos tropicais. As conseqüências da aplicação de ciclos de umedecimento e secagem em solos têm sido objeto de estudo de trabalhos e teses. No entanto, pouco se fez em termos de modelos descritivos e preditivos para a interação destes ciclos com os processos de formação de estrutura do solo.

Oliveira (1992) e Oliveira (1994) avaliaram a estabilidade de agregados submetidos a estes ciclos, relatando a fragmentação dos agregados expostos a ciclos de umedecimento e secagem. Jantsch (1997) concluiu, em experimento de laboratório, que as condições para surgimento de camadas adensadas estão relacionadas com a mineralogia e com os ciclos de umedecimento e secagem, que favorecem o fracionamento dos agregados. O trabalho de Santos (2000) evidenciou a formação de crostas estruturais e fendilhamento, associados à migração de colóides e hidratação diferencial, em experimento com variação dos tempos de secagem entre ciclos de umedecimento. Aluko \& Koolen (2000) estudaram um modelo para a ação das forças capilares na formação de pontes de interagregados no qual a força de coesão entre agregados é atribuída ao filme de umidade entre estes, sendo variável em função desta.

Mudanças microestruturais foram descritas por Tessier et al. (1990), em trabalho comparativo entre diversas velocidades de hidratação de argilas de mineralogia 1:1 e 2:1, em que a exposição de material caulinítico a uma rápida hidratação provocou o surgimento de agregados de partículas de tamanho entre 0,5 e $10 \mu \mathrm{m}$, enquanto o umedecimento lento provocou arranjo grosseiro face a face, sem descontinuidades além das originadas de rearranjo.

$\mathrm{O}$ uso de técnicas de análise de imagens para estudos quantitativos e qualitativos de estrutura de solo tem-se tornado mais comum na literatura, com o advento de equipamentos e programas mais acessíveis (McBratney et al., 1992; Hallett et al., 1995; Horn et al., 1995; Deleporte et al., 1997; Barros et al., 2001). Estas técnicas, associadas à micromorfologia, permitem o estudo quantitativo de modificações estruturais em amostras indeformadas, após seu preparo e sua montagem em lâminas (Moran, 1992). 
Este trabalho traz uma contribuição ao estudo experimental das alterações decorrentes de: (1) ciclos de umedecimento e secagem e (2) redução do tamanho dos agregados por moagem a seco, na estrutura de Latossolos. Visa também subsidiar o entendimento sobre a gênese da estrutura dos Latossolos. Como hipótese de trabalho, considerase que ciclos de umedecimento e secagem controlados provocam reestruturação diferenciada entre agregados integrais de Latossolos e agregados destruídos por moagem a seco.

\section{MATERIAL E MÉTODOS}

Utilizaram-se amostras de cinco Latossolos, do Banco de Solos do Departamento de Solos da Universidade Federal de Viçosa, previamente caracterizadas (Quadros 1 a 4 ).

A unidade experimental foi constituída por um cilindro de alumínio, com dimensões de 6,5 por $7,0 \mathrm{~cm}$, perfurado no fundo e forrado com papel-filtro, que continha o solo até uma altura de aproximada-

Quadro 1. Classificação, localização e material de origem dos solos

\begin{tabular}{|c|c|c|c|c|}
\hline Solo & Classificação anterior & Local de coleta & Localização & Material de origem \\
\hline L A & Latossolo Amarelo & Linhares (ES) & $\begin{array}{l}\text { S } 19007^{\prime} \\
\text { W } 40005^{\prime}\end{array}$ & Sedimentos do Grupo Barreiras \\
\hline LP & Latossolo Pálido & São Gotardo (MG) & $\begin{array}{l}\text { S } 19021^{\prime} 17^{\prime \prime} \\
W \quad 46007^{\prime} 04^{\prime \prime}\end{array}$ & Sedimento de cobertura detrítica laterítica \\
\hline LE & Latossolo Vermelho-Escuro & Barroso (MG) & $\begin{array}{l}\text { S } 21010^{\prime} 16^{\prime \prime} \\
\text { W } 43059^{\prime} 59^{\prime \prime}\end{array}$ & Calcário \\
\hline LR & Latossolo Roxo & Capinópolis (MG) & $\begin{array}{l}\text { S } 18043^{\prime} 41^{\prime \prime} \\
W 49033^{\prime} 20^{\prime \prime}\end{array}$ & Basalto \\
\hline $\mathrm{LF}$ & Latossolo Ferrífero & Belo Horizonte (MG) & $\begin{array}{l}\text { S } 20 \circ 07^{\prime} 40^{\prime \prime} \\
W 43 \circ 57^{\prime} 53^{\prime \prime}\end{array}$ & Itabirito \\
\hline
\end{tabular}

Fonte: Adaptado de Fernandes Filho (2000).

Quadro 2. Características físicas de amostras dos solos estudados

\begin{tabular}{|c|c|c|c|c|c|}
\hline Solo & Areia & Silte & Argila & Microestrutura & Relação silte/argila \\
\hline & \multicolumn{3}{|c|}{$\mathrm{g} \mathrm{kg}^{-1}$} & & \\
\hline L A & 660 & 0 & 340 & Grãos compactos coesos, microagregados & 0 \\
\hline LP & 50 & 90 & 860 & Microgranular e grãos interligados & 0,10 \\
\hline LE & 390 & 300 & 310 & Grãos interligados e parte microgranular forte & 0,97 \\
\hline L R & 400 & 130 & 470 & Parte microgranular forte e grãos interligados & 0,28 \\
\hline LF & 780 & 140 & 80 & Micronódulos grandes parte microgranular forte & 1,75 \\
\hline
\end{tabular}

Fonte: Adaptado de Fernandes Filho (2000).

Quadro 3. Características químicas de amostras dos solos estudados

\begin{tabular}{|c|c|c|c|c|c|c|c|c|c|c|c|c|c|c|}
\hline \multirow{2}{*}{ Solo } & \multicolumn{2}{|c|}{$\mathrm{pH}$} & \multirow{2}{*}{ C.O. } & \multirow{2}{*}{$\mathbf{P}$} & \multirow{2}{*}{$\mathbf{K}^{+}$} & \multirow{2}{*}{$\mathrm{Ca}^{2+}$} & \multirow{2}{*}{$\mathbf{M g}^{2+}$} & \multirow{2}{*}{$\mathrm{Al}^{3+}$} & \multirow{2}{*}{$\mathbf{H}+\mathbf{A} \mathbf{l}$} & \multirow{2}{*}{ SB } & \multicolumn{2}{|c|}{ CTC } & \multirow{2}{*}{ V } & \multirow{2}{*}{$\mathbf{m}$} \\
\hline & $\mathrm{H}_{2} \mathrm{O}$ & KCl & & & & & & & & & $t$ & $\mathrm{~T}$ & & \\
\hline & & & $\mathrm{g} \mathrm{kg}^{-1}$ & $\mathrm{mg} \mathrm{dm}-3^{-3}$ & 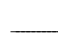 & 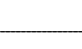 & 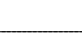 & 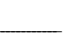 & $\mathrm{ol} \mathrm{dm}{ }^{-3}$ & & & . & 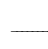 & 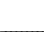 \\
\hline L A & 4,6 & 4,0 & 4,8 & 0,9 & 0,1 & 0,2 & 0,1 & 1,0 & 3,0 & 0,4 & 1,4 & 3,4 & 12 & 72 \\
\hline LP & 5,2 & 5,0 & 10,8 & 0,3 & 0,0 & 0,2 & 0,0 & 0,0 & 3,0 & 0,2 & 0,2 & 3,2 & 5 & 0 \\
\hline LE & 6,2 & 6,0 & 26,4 & 3,4 & 0,0 & 11,4 & 3,3 & 0,0 & 0,3 & 14,7 & 14,7 & 15,0 & 98 & 0 \\
\hline LR & 5,0 & 4,3 & 4,0 & 0,6 & 0,0 & 0,2 & 0,1 & 0,5 & 3,3 & 0,3 & 0,8 & 3,6 & 9 & 60 \\
\hline LF & 4,5 & 4,5 & 19,6 & 1,7 & 0,0 & 0,5 & 0,0 & 0,1 & 6,6 & 0,5 & 0,6 & 7,1 & 7 & 16 \\
\hline
\end{tabular}

Fonte: Adaptado de Fernandes Filho (2000). 
mente $2 \mathrm{~cm}$. As unidades experimentais foram colocadas sobre bases de placas de Petri, e o conjunto foi montado sobre bancada em casa de vegetação. Os tratamentos aplicados a cada solo, montados em duplicata, estão no quadro 5. O tratamento não desagregado constituiu-se de Terra Fina Seca ao Ar (TFSA) passada na peneira de $1,00 \mathrm{~mm}$. O tratamento desagregado constituiu-se de TFSA moída em almofariz de ágata e passada na peneira de $0,105 \mathrm{~mm}$. Nos tratamentos com adição de ácido húmico, foi utilizado ácido proveniente de turfa purificado, desidratado e moído em peneira de $0,053 \mathrm{~mm}$.

Após o preparo, foram iniciados os ciclos de umedecimento e secagem, realizados entre fevereiro e abril de 2000. Os ciclos consistiram na adição de água deionizada na base das placas de Petri. A água foi colocada em volume suficiente para que ocorresse saturação da amostra por capilaridade. Após a ascensão do líquido até à superfície, o excesso de água na base das placas era descartado. O material foi então seco ao ar por sete dias, reiniciando novo ciclo de umedecimento. Os tratamentos sem adição de água foram mantidos pelo mesmo período nas mesmas condições dos tratamentos com adição de água.

Ao final de 10 ciclos, o material foi levado para a estufa a $45{ }^{\circ} \mathrm{C}$ por uma semana e impregnado com resina de poliéster, segundo o método descrito por

\section{Quadro 4. Concentração mineralógica da fração argila efetuada pelo software ALOCA}

\begin{tabular}{|c|c|c|c|c|}
\hline Solo & Gibbsita & Caulinita & Goethita & Hematita \\
\hline & \multicolumn{4}{|c|}{$\mathrm{g} \mathrm{kg}^{-1}$} \\
\hline L A & 67 & 123 & 36 & 0 \\
\hline LP & 426 & 99 & 37 & 0 \\
\hline LE & 284 & 73 & 51 & 51 \\
\hline L R & 161 & 183 & 53 & 80 \\
\hline LF & 20 & 19 & 157 & 235 \\
\hline
\end{tabular}

Fonte: Adaptado de Fernandes Filho (2000).

Quadro 5. Tratamentos aplicados na amostras de cada solo estudado

\begin{tabular}{lcc} 
Identificação Moagem & $\begin{array}{c}\text { Aplicação } \\
\text { de ciclos }\end{array}$ & $\begin{array}{c}\text { Adição de } \\
\text { ácidohúmico }\end{array}$ \\
\hline
\end{tabular}

\begin{tabular}{lccc}
\hline$M_{0} A_{0}$ & - & - & - \\
$M_{0} A_{1}$ & - & $x$ & - \\
$M_{0} A 1+A H$ & - & $x$ & $x$ \\
$M_{1} A_{0}$ & $x$ & - & - \\
$M_{1} A_{1}$ & $x$ & $x$ & - \\
$M_{1} A_{1}+A H$ & $x$ & $x$ & $x$ \\
\hline
\end{tabular}

Castro (1985) e Murphy (1986). As amostras impregnadas foram deixadas para endurecimento e cura da resina por 60 dias. Após a cura, foi efetuado o corte das amostras em serra de disco diamantado e procedeu-se à confecção das lâminas delgadas (uma por amostra, duas por tratamento). As lâminas delgadas foram preparadas a partir dos cortes efetuados verticalmente no setor mediano dos blocos.

As lâminas delgadas foram fotografadas em microscópio ótico Olympus AX-70, sob luz plana e polarizada, magnificadas $40 x$ e $100 x$, e em lupa Olympus SZH com 7,5x de magnificação sob luz plana. As fotografias, obtidas com filme Kodak Gold 100 ASA, foram então reveladas e digitalizadas por meio de um scanner HP Scanjet 4C, para um formato matricial (Windows BITMAP).

As imagens digitais foram processadas com a utilização do programa QUANTIPORO (Fernandes Filho \& Viana et al., 2001), desenvolvido no DPS/ UFV, a partir do qual foram obtidas a porosidade total, a distribuição e a orientação de poros.

A descrição das feições morfológicas foi feita nas amostras após o preparo das lâminas. A partir dessa análise e dos dados obtidos por meio do programa QUANTIPORO, procedeu-se à interpretação qualitativa dos resultados e foi feita uma proposta para explicar as modificações observadas.

Não foram efetuadas comparações estatísticas entre os tratamentos com e sem moagem dos agregados, pois o peneiramento removeu a fração areia grossa e média ( $>0,105 \mathrm{~mm}$ ), resultando em um fator de variação adicional. Nas comparações qualitativas, considerou-se baixo o teor de areia nestes solos (exceto o LA), sendo sua atividade, em termos físicos, muito inferior à das frações mais finas. Os resultados de porosidade são a média das duas repetições de cada tratamento.

\section{RESULTADOS E DISCUSSÃO}

\section{Descrições micromorfológicas das amostras}

As amostras não moídas apresentam a estrutura microgranular característica dos Latossolos, mais evidentes nos materiais gibbsíticos (LE, LR e LP, Figuras 4 e 5). No LF, os agregados apresentam-se sob a forma de micronódulos, muito resistentes à moagem e com concreções de ferro (Figura 4c). O LA apresenta estrutura coesa, com menor expressão de arredondamento e agregados arestados e soldados, condizente com sua mineralogia caulinítica.

\section{Principais alterações observadas \\ Mudanças na porosidade total}

As variações na porosidade podem ser observadas nas figuras de $1 \mathrm{a} 5$. Em todos os tratamentos sem 
desagregação, não houve variação expressiva da porosidade total ou da porosidade por camadas entre os tratamentos mantidos secos e os tratamentos que sofreram os 10 ciclos de umedecimento e secagem (imagens nas Figuras 1 a 5 e gráficos da porosidade na Figura 6).
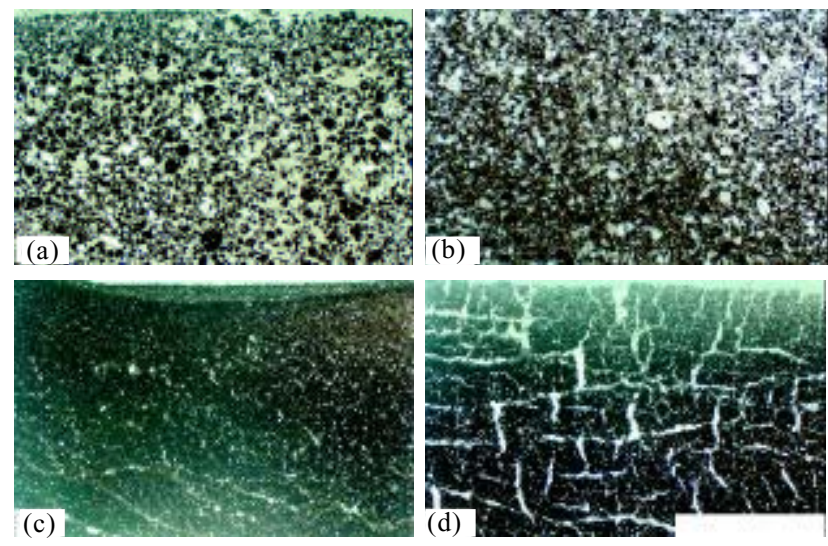

Figura 1. Efeito dos ciclos de umedecimento e secagem: (a) Tratamento LE $M_{0} A_{0}$ não desagregado, sem adição de ácido húmico e mantido seco. (b) Tratamento LE $M_{0} \mathbf{A}_{0}$ não desagregado, sem adição de ácido húmico, após dez ciclos. (c) Tratamento $L E M_{1} A_{0}$ desagregado, sem adição de ácido húmico e mantido seco. (d) Tratamento LE $M_{1} A_{0}$ desagregado, sem adição de ácido húmico após 10 ciclos. Fotomicrografias em lupa, ampliação $7,5 x$ (barra: $5 \mathrm{~mm}$ ).
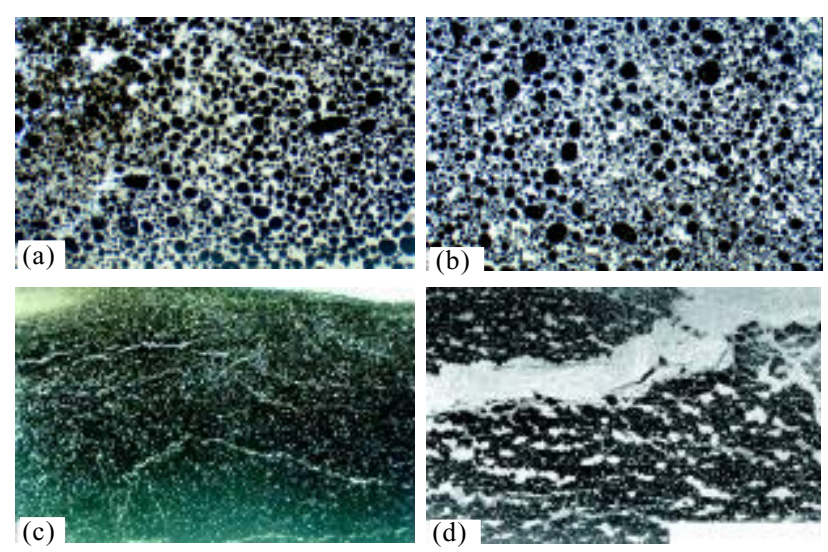

(c)

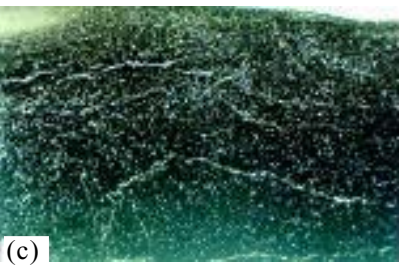

(d) 2 oxtext

Figura 2. Efeito dos ciclos de umedecimento e secagem: (a) Tratamento LF $M_{0} A_{0}$ não desagregado, sem adição de ácido húmico e mantido seco. (b) Tratamento $L F M_{0} A_{0}$ não desagregado, sem adição de ácido húmico, após dez ciclos. (c) Tratamento $L F M_{1} A_{0}$ desagregado, sem adição de ácido húmico e mantido seco. (d) Tratamento LF $M_{1} A_{0}$ desagregado, sem adição de ácido húmico após 10 ciclos. Fotomicrografias em lupa, ampliação $7,5 x$ (barra: $5 \mathrm{~mm}$ ).
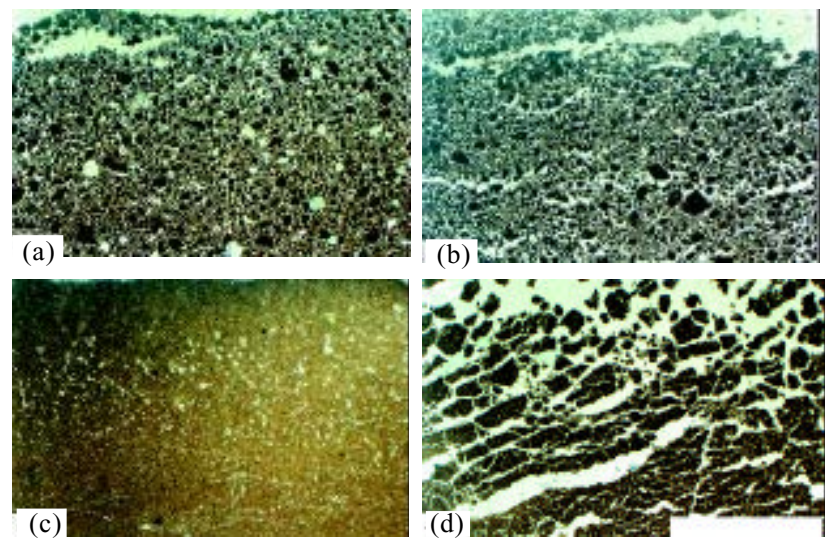

Figura 3. Efeito dos ciclos de umedecimento e secagem: (a) Tratamento LP $M_{0} A_{0}$ não desagregado, sem adição de ácido húmico e mantido seco. (b) Tratamento LP $M_{0} A_{0}$ não desagregado, sem adição de ácido húmico, após dez ciclos. (c) Tratamento $L P M_{1} A_{0}$ desagregado, sem adição de ácido húmico e mantido seco. (d) Tratamento LP $M_{1} A_{0}$ desagregado, sem adição de ácido húmico após 10 ciclos. Fotomicrografias em lupa, ampliação 7,5x (barra: $5 \mathrm{~mm}$ ). A seta em (d) indica um poro planar.

Por outro lado, nos tratamentos em que os agregados foram destruídos, ocorreu significativa mudança na quantidade de poros e na distribuição destes após os ciclos. A mudança do padrão observado entre os tratamentos pode ser atribuída a um mecanismo de acomodação e rearranjo das partículas após os ciclos. Os agregados neoformados, nestes tratamentos, apresentaram-se como unidades maiores (blocos angulares ou prismas, como no LR e LP, ou placas e lâminas em cunha, em LA, LF e LR), com macroporosidade entre estas unidades e uma microporosidade interna discernível, apesar de não quantificável pela resolução utilizada.

A redução do tamanho dos agregados levou a uma acomodação inicial destes, resultando em baixa macroporosidade. Esta acomodação pode ser evidenciada nas fotomicrografias, que mostram a estrutura interna dos agregados (Figuras 4 e 5).

A hidratação do material levou à formação de filmes de água entre os agregados, cujas superfícies específicas foram ampliadas pela redução do tamanho. A exposição de cargas do interior dos agregados após sua fragmentação também pode ter auxiliado a hidratação destes (Oliveira, 1992). Com a desidratação, houve incremento progressivo da tensão na massa, até à ruptura em forma de fendas verticais e, ou, horizontais, a partir de pontos de fraqueza na superfície. Ao atingir a umidade de equilíbrio, as partículas se reorganizaram, podendo ter ocorrido a formação de ligações estáveis entre os agregados (Bartoli et al., 1992; Iwata et al., 1988). Não houve evidência de dispersão de argila ou movimentos de agregados ou partículas. As hidratações posteriores não levaram ao fechamento 

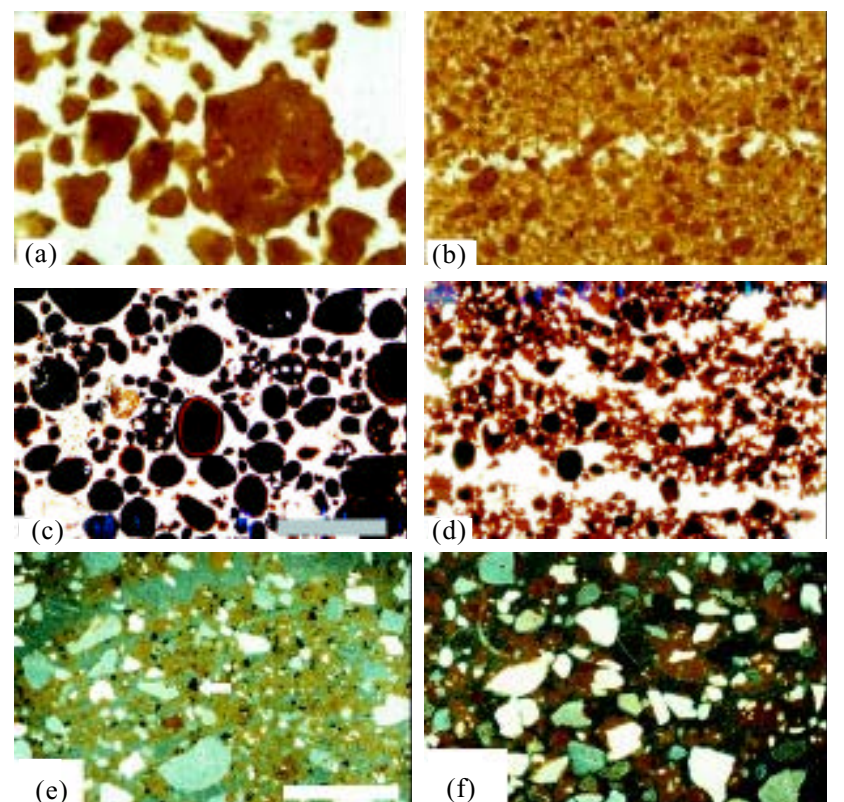

(e)

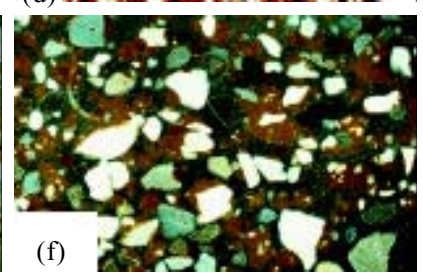

Figura 4. Fotomicrografias em microscópio ótico: (a) Tratamento LP $M_{0} A_{0}$ não desagregado, sem adição de ácido húmico e mantido seco ampliada 100x. (b) Tratamento LP $M_{1} A_{0}$ desagregado, sem adição de ácido húmico, após 10 ciclos de umedecimento e secagem ampliada 100x. (c) Tratamento $L F M_{0} A_{0}$ não desagregado, sem adição de ácido húmico e mantido seco, ampliada 40x (barra: $100 \mu \mathrm{m}$ ). (d) Tratamento $L F M_{1} A_{0}$ desagregado, sem adição de ácido húmico após 10 ciclos ampliada 100x. (e) Tratamento LA $M_{1} A_{1}+A H$ desagregado, com adição de ácido húmico e mantido seco, ampliada 100x (barra: $250 \mu \mathrm{m}$ ). (f) Tratamento $L A M_{0} A_{0}$ não desagregado, sem adição de ácido húmico e mantido seco ampliada 100x. Na seta em (e), partícula de ácido húmico.

das fendas, conforme observado durante o experimento, e os blocos e as crostas formados permaneceram aparentemente estáveis ao longo do experimento.

Embora esta estabilidade não tenha sido medida, a estrutura formada a partir desta reorganização não se modificou significativamente apenas com a reidratação, não retornando à estrutura original após o fim dos ciclos. A diferença entre os resultados dos tratamentos parece estar relacionada com a maior superfície específica, com a forma mais irregular e com o menor tamanho dos agregados menores, que possibilitaram o surgimento de maior quantidade de filmes de hidratação e maior capacidade de retração e acomodação da massa de agregados. O tamanho menor dos agregados também os tornou mais susceptíveis às forças da tensão superficial entre agregados, decorrente da menor relação entre sua massa e a tensão do filme capilar.

Não foi observado efeito da aplicação de ácido húmico em nenhum dos tratamentos ou solos. Esse fato pode ser atribuído à não-dissolução deste ácido
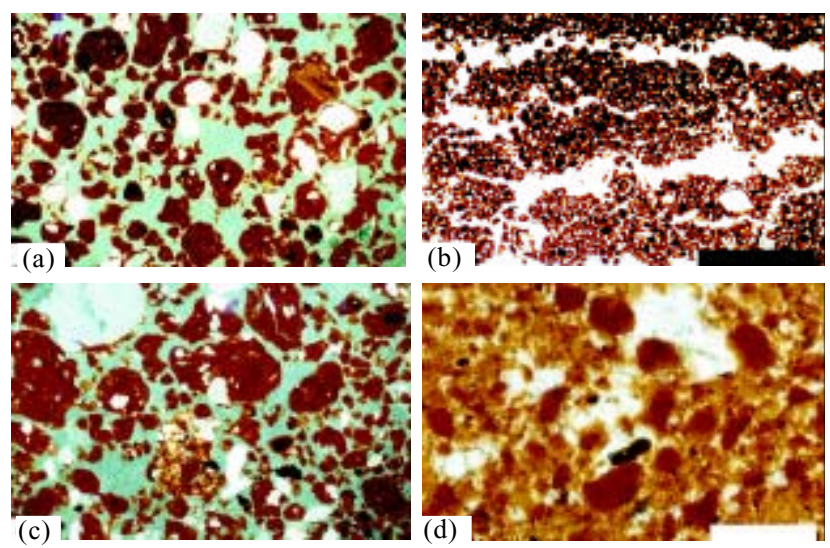

Figura 5. Fotomicrografias em microscópio ótico: (a) Tratamento LE $M_{0} A_{0}$ não desagregado, sem adição de ácido húmico e mantido seco ampliada 40x. (b) Tratamento LE $M_{1} A_{0}$ desagregado, sem adição de ácido húmico após 10 ciclos de umedecimento e secagem ampliada 40x (barra: $250 \mu \mathrm{m}$ ). (c) Tratamento LR $M_{0} \mathbf{A}_{0}$ não desagregado, sem adição de ácido húmico após dez ciclos ampliada 40x. (d) Tratamento $L R M_{1} A_{1}$ desagregado, com adição de ácido húmico após 10 ciclos ampliada 200x (barra: $50 \mu \mathrm{m})$.

nos tratamentos, em virtude de sua elevada peptização e baixa solubilidade, permanecendo como partículas discretas (Figura 4e), apesar do reduzido tamanho de partícula $(<0,053 \mathrm{~mm})$.

\section{Mudanças na forma e orientação dos poros}

$\mathrm{O}$ aparecimento de poros planares pode ser observado nas imagens (Figuras 1d, 3d e 5b) e confirmado com a análise da orientação dos poros, em que são mostradas as orientações dos eixos maiores dos poros de maior área em relação à horizontal (Figura 7).

Nos tratamentos que sofreram desagregação, nota-se a formação de uma rede de poros planares, de orientação paralela ou subparalela à superfície. Nos solos LE e LR, houve também a formação de poros alongados de orientação vertical ou subvertical (Figura 1d). A extensão dos poros também variou entre os solos, desde poros quase elípticos no LF (Figura 2d) até extensos poros planares, formando placas ou crostas descontínuas ou fraturadas, como no LP (Figura 3d).

O surgimento desses poros parece estar associado às tensões internas surgidas com a progressiva perda de água pela superfície e a retração da massa dos agregados (Cherkov \& Ravina, 1999). Segundo Tessier et al. (1990), o rápido umedecimento de materiais cauliníticos provoca o surgimento de fraturas, por causa de pressões de bolhas de ar aprisionadas, que podem escapar se o umedecimento foi suficientemente lento. As diferenças entre os 


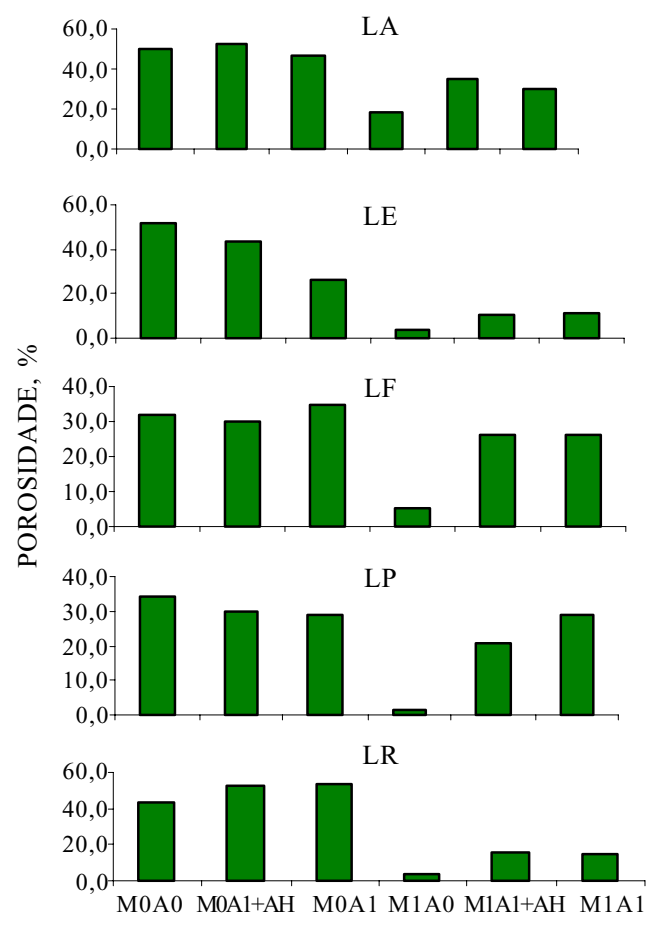

Figura 6. Resultados de porosidade para os solos LA, LP, LE, LR e LF. MOA0 = tratamento não desagregado mantido seco. M1A0 = tratamento desagregado mantido seco. M0A1 = tratamento não desagregado após dez ciclos. M1A1 = tratamento desagregado após 10 ciclos. $+\mathrm{AH}=$ adição de ácido húmico.

padrões de poros surgidos, como os poros predominantemente planares em LA, LF e LR, em relação ao padrão reticulado de poros ortogonais de LP e LE, podem estar associadas à mineralogia dos solos, mais gibbsítica nos últimos. Maiores estudos são necessários para que se explique esse comportamento, bem como suas implicações na estabilidade e reorganização dos agregados.

\section{Resultados das alterações da porosidade nos solos LP e LR}

As análises foram efetuadas em cada tratamento separadamente, pois o peneiramento ocasionou a separação da fração areia média e grossa. Embora para o Latossolo Ámarelo (LP) esta fração seja muito pequena e menos ativa, por seu tamanho e sua superfície específica, a comparação entre os tratamentos moídos e não moídos se fez apenas de forma qualitativa.

Os resultados de porosidade para os dois solos evidenciam a estabilidade estrutural da macroporosidade das parcelas dos agregados não moídos indicada pelas pequenas diferenças entre os valores de porosidade antes e depois dos ciclos (Figura 6). Aparentemente, o tamanho e a forma desses agregados não permitem grandes ajustes por efeitos
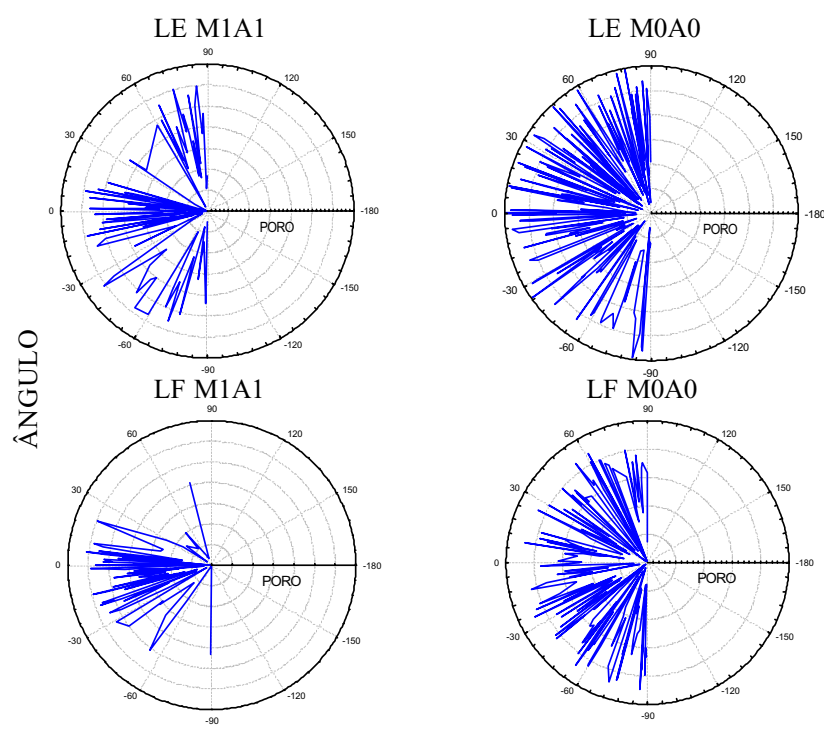

Figura 7. Espectros de orientação de poros principais dos tratamentos LE M1A1 (no alto, à esquerda) e LE MOAO (no alto, à direita) de LF M1A1 (em baixo, à esquerda) e LF M0A0 (em baixo, à direita).

das forças de tensão superficial do filme de água capilar. O material comporta-se como previsto para solos não-expansivos de estrutura rígida, onde não são geradas tensões mecânicas por umedecimento entre as partículas (Jury et al., 1991). Presume-se que a existência de poros maiores tenha permitido rápida perda de umidade e tensões menores na massa em razão do maior diâmetro destes.

A diferença dos resultados entre os tratamentos não desagregados mantidos secos e aqueles submetidos aos ciclos pode ser atribuída a pequenas reacomodações entre os agregados. No caso dos agregados moídos, o surgimento de poros e fendas pela retração da massa de agregados durante os eventos de secagem favoreceu o significativo aumento da porosidade, embora a observação da microestrutura dos blocos e das crostas resultantes dessa expansão indique a manutenção de uma microporosidade entre agregados antes e depois dos ciclos. Os dados mostram que os eventos de umedecimento permitiram a acomodação das partículas menores e mais irregulares e que a existência de filmes de umidade nos microporos deu origem a tensões internas maiores durante os eventos de secagem, levando ao fendilhamento da massa. O material terse-ia se comportado, no primeiro ciclo, de forma similar a um solo de argila expansiva, permitindo reorientação de partículas inicialmente dispostas aleatoriamente com o umedecimento e seu rearranjo no processo de secagem (Iwata et al., 1988). Após o estabelecimento do equilíbrio ao final dos primeiros ciclos, o solo tornaria a se comportar como um solo não-expansivo de estrutura rígida (Jury et al., 1991). 
A relação entre o tamanho e a massa dessas partículas e as forças da tensão superficial da água e elétrica das superfícies também deve ser levada em consideração (Snyder, 1990). Uma redução do diâmetro de dez vezes em relação ao tratamento integral resulta em redução de 1.000 vezes na massa esperada para as partículas, considerando a mesma densidade, e incremento de 100 vezes na área específica, considerando os agregados esféricos. Aliado a isso, pode ocorrer uma mudança de forma, com incrementos da angulosidade e da rugosidade e redução da esfericidade, influindo na área de contato entre as partículas e as forças de atrito entre partículas. Disso resulta maior susceptibilidade às demais forças atuantes durante os processos de umedecimento e secagem, permitindo movimentos de rotação e interpenetração de partículas (Panayiotopoulos, 1989).

A atração entre os agregados durante o processo de secagem pode ser explicada pelo surgimento de forças de atração relacionadas com o filme capilar entre as partículas. No material saturado, o espaço entre os agregados encontra-se completamente preenchido por água e a força de atração é zero. Com a perda de água, ocorre a formação do menisco com raio negativo, que causa o surgimento de uma força capilar de atração. Essa força é máxima, quando o raio do menisco tende a zero. Esta força de atração pode ser estimada por:

$$
\mathrm{F}=\pi \mathrm{R}_{1} \delta\left(1-\mathrm{R}_{1} / \mathrm{R}_{2}\right)
$$

em que $R_{1}$ e $R_{2}$ são os raios principais de curvatura do menisco e $\delta$, a tensão superficial do líquido (Schukin et al., 1988).

Essa tensão fornece a energia para o deslocamento e a acomodação por deslizamento e translação dos agregados. A tração resultante sobre a massa de agregados provoca então a ruptura e o fendilhamento.

\section{CONCLUSÕES}

1. A moagem e a destruição dos agregados provocaram mudanças no padrão de estrutura após a aplicação de ciclos de umedecimento e secagem.

2. A microestrutura e o padrão de porosidade surgidos em Latossolos após a moagem diferiram da microestrutura primária desta classe de solos.

3. A evidência experimental não indicou qualquer tendência à reversão para a estrutura original, com dez ciclos de umedecimento e secagem, evidenciando que a gênese da microestrutura latossólica depende de outros fatores, além da composição mineralógica e dos atributos físico-químicos.

4. As mudanças no padrão de estrutura ocorreram em todos os solos, com diferenças na expressão de poros planares, possivelmente devidas à diferença de mineralogia.

\section{AGRADECIMENTO}

À CAPES pelo apoio financeiro.

\section{LITERATURA CITADA}

ALUKO, O.B. \& KOOLEN, A.J. The essential mechanics of capillary crumbling of structured agricultural soils. Soil Till. Res., 55:117-126, 2000.

BARRos, E.; CURMI, P.; HALlAIRE, V.; CHAUVEL, A. \& LAVELLE, P. Role of macrofauna in the transformation and reversibility of soil structure of an Oxisol during forest to pasture conversion. Geoderma, 100:193-213, 2001.

BARTOLI, F.; BURTIN, G. \& GUÉRIF, J. Influence of organic matter on aggregation in Oxisols rich in gibbsite or in goethite. II. Clay dispersion, aggregate strength and waterstability. Geoderma, 54:259-274, 1992.

CASTRO, S.S. Impregnação de amostras de solo para confecção de lâmina delgada. B. Inf. Soc. Bras. Ci. Solo, 10:44, 1985.

CHERKOV, V.Y. \& RAVINA, I. Morphology of horizontal cracks in swelling soils. Theor. Appl. Fract. Mec., 31:19-29, 1999.

DELEPORTE, S.; HALLAIRE, V. \& TILLIER, P. Application of image analysis to a quantitative micromorphological study of forest humus. Eur. J. Soil Biol., 33:83-88, 1997.

FERNANDES FILHO, E.I. \& VIANA, J.H.M. QUANTIPORO: um novo programa para tratamento e quantificação de imagens digitais para aplicações em ciência do solo. In: CONGRESSO BRASILEIRO DE CIÊNCIA DO SOLO, 28., Londrina, 2001. Resumos. Londrina, Sociedade Brasileira de Ciência do Solo. 2001. p.224.

FERNANDES, R.B.A. Atributos mineralógicos, cor, adsorção e dessorção de fosfatos em Latossolos do sudeste brasileiro. Viçosa, Universidade Federal de Viçosa, 2000. 265p. (Tese de Doutorado)

HALleTt, P.D.; DEXTER, A.R. \& SEVILlE, J.P.K. Identification of pre-existing cracks on soil fracture surfaces using dye. Soil Till. Res., 33:163-184, 1995.

HORN, R.; DOMZAL, H.; SLOWIN'SKA-JURKIEWICZ, A. \& van OUWERKERK, C. Soil compaction processes and their effects on the structure of arable soils and the environment. Soil Till. Res., 35:23-36, 1995.

IWATA, S.; TABUCHI, T. \& WARKERTIN, B.P. Soil-water interactions. New York, Marcel Dekker, 1988. 380p.

JANTSCH, R.L. Estado de agregação de materiais de Latossolos submetidos a calagem em diferentes condições de temperatura e umidade relativa. Viçosa, Universidade Federal de Viçosa, 1997. 78p. (Tese de Mestrado)

JURY, W.A.; GARDNER, W.R. \& GARDNER, W.H. Soil physics. New York, John Willey \& Sons, 1991. 328p.

McBRATNEY, A.B.; MORAN, C.J.; STEWART, J.B.; CATTLE, S.R. \& KOPPI, A.J. Modifications to a method of rapid assessment of soil macropore structure by image analysis. Geoderma, 53:255-274, 1992. 
MORAN, C.J. Image processing and soil micromorphology. In: RINGROSE-VOASE, A.J. \& HUMPHREYS, G.S., eds. Soil micromorphology: studies in management and genesis. In WORKING MEETING ON SOIL MICROMORPHOLOGY, 9., Towmsville, 1992. Proceedings. Amsterdam, Elsevier, 1992. p.459-482.

MURPHY, C.P. Thin section preparation of soils and sediments. Berkhamsted, A. B. Academic Publishers, 1986. 149p.

OLIVEIRA, T.S. Efeitos dos ciclos de umedecimento e secagem sobre propriedades físicas e químicas de quatro Latossolos brasileiros. Viçosa, Universidade Federal de Viçosa, 1992. 102p. (Tese de Mestrado)

OLIVEIRA, L.C.A. Comportamento de colóides e microagregados em colunas de materiais de dois Latossolos submetidos a sucessivos ciclos de umedecimento e secagem. Viçosa, Universidade Federal de Viçosa, 1994. 63p. (Tese de Mestrado)
PANAYIOTOPOULOS, K.P. Packing of sands - A review. Soil Till. Res., 13:101-121, 1989.

SANTOS, C.S.V. Formação de camadas superficiais adensadas em solo argiloso em resposta a flutuações de umidade. Viçosa, Universidade Federal de Viçosa, 2000. 70p. (Tese de Doutorado)

SCHUKIN, E.D.; PERTSOV, A.V. \& AMÉLINA, E.A. Química coloidal. Moscou, Mir, 1988. 384p.

SNYDER, V. Scaling of mechanical stresses in soils. In: Scaling in soil physics: principles and applications. HILLEL, D. \& ELRICK, D.E., eds. Madison, Soil Science Society of America, 1990. p.73-108.

TESSIER, D.; BEAUMONT, A. \& PEDRÓ, G. Influence of clay mineralogy and rewetting rate on the clay microstructure. In: Soil micromorphology: a basic and applied science. INTERNATIONAL WORK MEETING OF SOIL MICROMORPHOLOGY, 8., San Antonio, 1988. Proceedings. Amsterdam, Elsevier Science, 1990. p.191-198. 